\title{
Apparatus for in situ measurement of light scattering during heat-treatment
}

Klaus Huntebrinker and Bärbel WemheuerMladen Grubić and Ulrich Würz

Citation: 60, 953 (1989); doi: 10.1063/1.1140352

View online: http://dx.doi.org/10.1063/1.1140352

View Table of Contents: http://aip.scitation.org/toc/rsi/60/5

Published by the American Institute of Physics

\section{$\oplus$ SHIMADZU Powerful, Multi-functional UV-Vis-NIR and} Excellence in Science FTlis Spectjophotometers

Providing the utmost in sensitivity, accuracy and resolution for applications in materials characterization and science

- Photovoltaics - Ceramics

- Polymers

- Coatings

- Thin films

- Paints

Click here for accurate, cost-effective laboratory solutions

- DNA film structures

- Packaging materials

- Nanotechnology
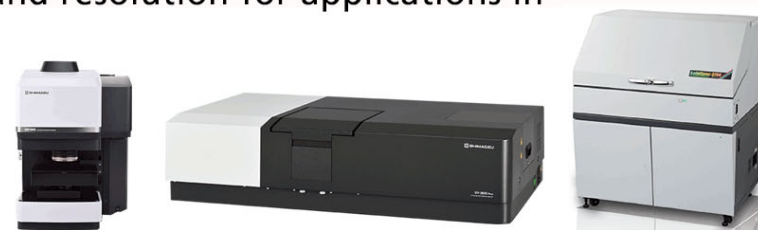


\title{
Apparatus for in situ measurement of light scattering during heat-treatment
}

\author{
Klaus Huntebrinker and Bärbel Wemheuer \\ Institut für Nichtmetolische Werkstoffe, Technische Universität Clausthal, Zehntherstr. $2 a$, D.3392 \\ Clausthal-Zellerfeld, Federal Republic of Germany \\ Maden Grubit and Uirich Würz \\ Max-Planck-Institut für Biophysikalische Chemie, Postfach 2841, D-3400 Götingen 1, Federal Republic of \\ Germany
}

(Received 2 A ugust 1988; accepted for publication 13 December 1988)

\begin{abstract}
A fully automated apparatus is described for the in situ measurernent of light scattering in glass forming systems during heat treatment. Its furnace and regulator provide high-temperature change rates of the order of several $\mathrm{K} / \mathrm{s}$. Additionally the sample temperature can be kept constant to within $0.1 \mathrm{~K}$ for several days in ranges up to $900^{\circ} \mathrm{C}$. A He-Ne laser provides linearly polarized light and the light scattered under $90^{\circ}$ (or $15^{\circ}$ ) is detected using photodiodes and lock-in amplifiers.
\end{abstract}

Investigations of the demixing of quasibinary glass melts normally are made at room temperature with quenched samples. 'They are, however, easily impaired by artifacts introduced during sample preparation or quenching procedures. ${ }^{2}$ Therefore, an apparatus for the in situ measurement of light scattering during the different stages of the transformation seemed desirable, coping with the following demands. Two scattering angles, $15^{\circ}$ and $90^{\circ}$, should be attainable. High heating and cooling rates of the sample must be possible, since temperature has to be changed rapidly between the different steps of heat treatment, typically comprising homogenization, nucleation, and growth periods. The temperature should be controllable within fractions of a Kelvin for long periods of time in the whole region between room temperature and about $900^{\circ} \mathrm{C}$. Within the entire scattering volume, temperature differences must not exceed the same limits. These requirements are not fully mot by known devices, ${ }^{3,4}$ but may be achieved more easily by reducing sample size which, in turn, allows the use of a smaller furnace. Sufficient reduction of the furnace may lead to the use of commercially available power amplifiers. To diminish temperature gradients in the sample and to make fabrication easy, we chose cylindrical symmetry as the basis of the design (see Fig. 1).

The sample, a disk of slightly less than $1.00 \mathrm{~cm}$ diameter and typically $0.5 \mathrm{~cm}$ thickness, is positioned in the center of the furnace. Both sides and a fiat part of the disk circumference (opposing the detector for the scattered light) are polished to prevent light scattering from the surfaces. The sample holder consists of a 1 -mm-thick-walled tube of $3.0 \mathrm{~cm}$ length made of a Pt-5 wt. \% Au alloy. Its composition is chosen such that typical glass samples do not wet it, which allows easy replaccment. This tube, together with the sample in its center, is fixed on top of a rod and introduced together with the sample into a sleeve made of glass ceramics (Macor from Corning glass works). There it is released in the very center of the furnace. Silicon rubber O-rings at either end of the glass ceramic sleeve allow for thermal expansion. Holes at the sleeve circumference serve as an inlet and outlet for the applied atmosphere. Heating wires are wound around the tube in its central par, together with a thermoelement, which serves as a temperature sensor.

Three cylindrical heat shields surround the tube; vertical ones with the shape of circular disks are introduced into the conical part of the glass ceramic tube and fixed by spacers. Distances between shields are small enough to suppress convection. The glass ceramic tube and heat shields are held in place by two brass parts, connected by three metal rods. This arrangement is introduced into a brass cylinder, surrounded by water jackets. Seals against atmosphere and water are made from Viton $\mathrm{O}$-rings. Access to the interior is provided by two brass cones on either end of the fumace. They bear gas inlet and outlet, the gas tight windows for the primary beam, and the photodiodes for the detection of primary intensity and of the light scattered under small angle. The primary beam can be weakened by calibrated filters. An additional holder for the $90^{\circ}$ scattering intensity photodiode is mounted on the mantle of the cylinder. Its unbe-shaped diaphragn aims at the concentric holes in the heat shields, the glass ceramic tube, and the very sample holder. The whole assembly $(10 \mathrm{~cm} 0 . \mathrm{d}$.) fits into commercial optical bench systems.

Applying power of about $50 \mathrm{~W}$ will raise the sampie temperature to $920^{\circ} \mathrm{C}$ in an argon atmosphere at a pressure sightly higher than nomal. At $800^{\circ} \mathrm{C}$, the maximum heating and cooling rates are 1 and $5 \mathrm{~K} / \mathrm{s}$, respectively. Temperature is measured via the emf of the thermocouple, a cold junction compensator (AD595 from Analog Devices), and the ADC (AD572 from Analog Devices) with a resolution of $0.25 \mathrm{~K}$. It is calibrated at the melting temperature of $\mathrm{Al}$ $\left(660.4^{\circ} \mathrm{C}\right)$ by observing the collapse of a piece of $\mathrm{Al}$ foil situated in the very center of the fumace between two glass samples of half the normal thickness. We estimate spatial temperature differences in the scattering volume to be less than $0.1 \mathrm{~K}$.

The output of the ADC is fed via an IEC-488 interface into a microcomputer. A slightly modified PID algorithm allowing for additional digital fitering of noise is implemen- 


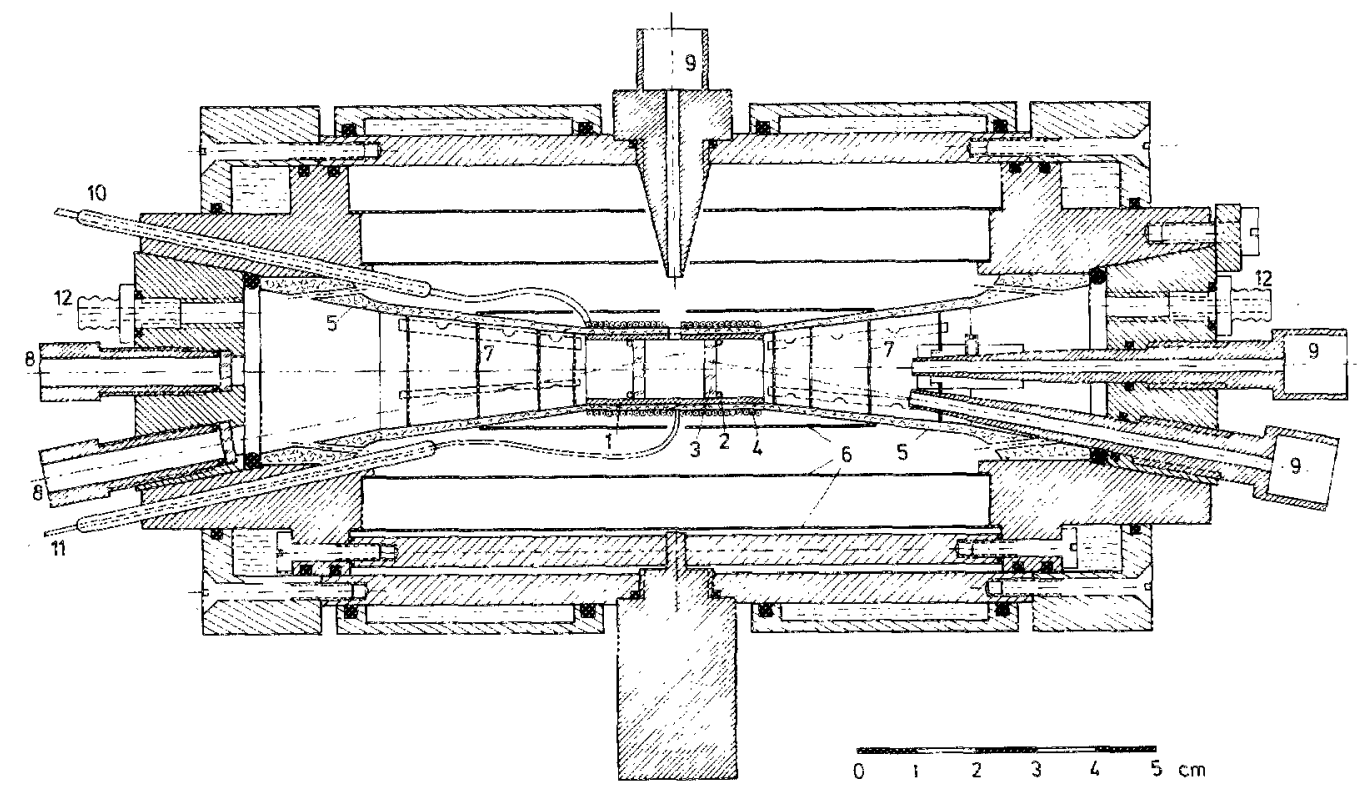

Fig. 1. Furnace. 1: Pt tube serving as sample holder; 2: Pt-wire rings; 3: silica glass window (optiona); 4: thermocoax heating wire ( 1 Nc Ac 10 from Philips); 5: glass ceramic tube; 6, 7: heating shields; 8: primary beam entrance; 9: space for photodiodes; 10: heating wire junction; 11:2 AB Ac 05 Chromel-Alumel thermoelement junction; 12 inert gas inlet. $O$-rings show up as black dots in the graph.

ted. The heating power is calculated and reported via an IEC-488 bus and a 16-bit DAC to the power amplifier (3572 Burr-Brown, max. $60 \mathrm{~W}$ ), connected to the heating wires ( $15 \Omega$ ) of the furnace. The control system is regarded as a continuous one, since the sampling frequency $(1 \mathrm{~Hz})$ turned out to be sufficiently high. Time constants of the fumace vary considerably over the temperature range involved in typical nucleation and growth experiments, hence an adaptive regulation scheme seemed appropriate. Using the gain scheduling scheme, ${ }^{5}$ we were able to attain well-defned nucleation periods with negligible overshoot or lag in temperature. A more sophisticated approach will be described elsewhere. ${ }^{6}$ The regulation loop is passed through in less than 1 $\mathrm{s}$. The temperature program can be adopted to experimental requirements with great flexibility.

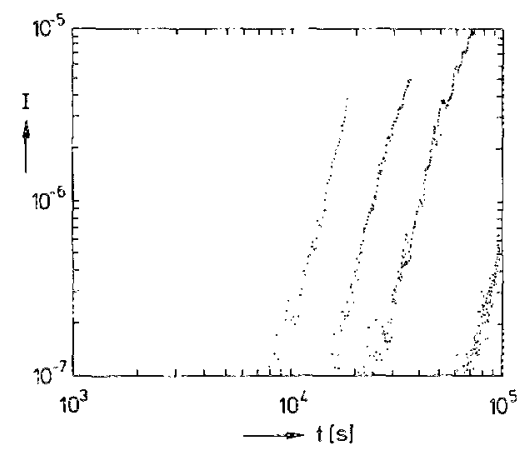

FIG. 2. Light scattering intensity $I\left(90^{\circ}, t\right)$ of $13.1 \mathrm{~mol} \% \mathrm{Na}_{2} \mathrm{O}, 11.0 \mathrm{~mol} \%$ $\mathrm{CaO}, 75.9 \mathrm{~mol} \% \mathrm{SiO}_{2}$ glass during diffusion controlled growth at $650^{\circ} \mathrm{C}$. Nucleation temperature was $650^{\circ} \mathrm{C}$; nucleation times were (from left to right) $60,30,15$, and $7.5 \mathrm{~min}$.
A 4.5-mW He-Ne laser (PL 750 P from Polytec) provides linearly polarized light. A chopper modulates the primary beam with a frequency of about $75 \mathrm{~Hz}$. The standard light detection system employs three photodiodes, detecting the intensities of incident, transmitted, and scattered light. Their output is fed via preamplifiers into lock-in amplifiers, working with the chopper frequency as reference. Thus, the glow of the red-hot furnace is not registered. Data are collected with the help of a microcomputer and processed numerically. The apparatus has been in operation almost continuously for about six years and proved reliable.

Figure 2 shows a series of typical measurements. ${ }^{7}$ The ratio $I\left(90^{\circ}, t\right) / I\left(0^{\circ}, t\right)$ is plotted versus growth time in a double logarithmic plot. There is some background intensity due to spatial concentration variations in the sample and/or light refiected or scattered in the apparatus. A steep increase shows up when the nuclei grow to sizes detectable with light scattering. The proportionality to $t^{5}$ is attributed to the growth of a spherical precipitate of silica glass surrounded by a diffusion zone. The distance between the straight lines contains information about the number of nuclei formed. ${ }^{3}$ This work was supported by the SFB 126 .

'Phase Separation in Glass, edited by O. V. Mazurin and E. A. Porai-Koshits (North-Holland, Amsterdam, 1984).

2J. P. Kerwawycz and M. Tomozawa, J. Appl. Phys. 51, 4391 (1980).

${ }^{3}$ C. Raptis, J, Phys, E 16, 749 (1983).

${ }^{4}$ H. Hagemann, J. L. Clignez, F. Rouge, and H. Bill, J. Phys. E 19, 199 (1986).

${ }^{s_{\mathrm{K}}}$. J. Åström, Proc. IEEE 75, 187 (1987)

"M. Grubic (to be published in Rev. Sci. Instrum.).

${ }^{7}$ K. Huntebrinker, U. Würz, and G. H. Frischat (to be published in J. Noncryst. Solids). 